'llu. Revista de Ciencias de las Religiones

ISSN: $1135-4712$

http://dx.doi.org/10.5209/ILUR.57412

\title{
Solidaridad y religión. La acción social en las confesiones minoritarias en España. El caso de Aragón
}

\author{
Carlos Gómez Bahillo하 Diana Valero Errazu²
}

Recibido: 22 de junio de 2016 / Aceptado: 5 de junio de 2017

Resumen. Las iglesias y comunidades de creyentes viven su fe a través de una actitud y disposición solidaria hacia los colectivos con dificultades, por lo que se convierten en una red social de apoyo a los más necesitados. Gracias a ello, los procesos de inserción e integración social se suavizan y se solventan de forma más satisfactoria, siendo especialmente importantes para los problemas que se generan cuando se comienza un nuevo proyecto vital o se accede a una nueva sociedad, como es el caso de la inmigración. Esta investigación analiza el papel que desempeñan las redes sociales asistenciales de las confesiones minoritarias y la acción social que desarrollan. Tras una reflexión sobre la dimensión social del concepto de solidaridad y de la función solidaria de la religión, se recogen las vivencias de los protagonistas, a través de entrevistas semiestructuradas, sobre el papel que tiene la comunidad de creyentes en la inserción social de los nuevos pobladores.

Palabras clave: solidaridad; inserción; acogida; red social.

\section{[en] Solidarity and religion. Social action in minority religions in Spain. The case of Aragón}

\begin{abstract}
Churches and communities of believers live their faith through a disposition and supportive attitude toward disadvantaged groups, this way they become a social network of support to the neediest. The processes of social integration are softened and problems arising are therefore solved more successfully, this is especially important when a new vital project starts or someone enters in a new society, as in the case of immigration. This research analyzes the role of social welfare networks of minority religions and the social action they do. After a reflection on the social dimension of the concept of solidarity and the function of solidarity in religion, we collect the experiences of the protagonists, through semi-structured interviews on the role of the community of believers in the social integration of newcomers.
\end{abstract}

Keywords: solidarity; integration; hosting; social network.

Sumario. 1. Planteamiento. 2. Metodología. 3. Fundamentación teórica y precisión conceptual. 4. Institucionalización de la solidaridad en las confesiones minoritarias. 5. La acción social en las confesiones minoritarias desde la perspectiva de sus actores. El caso de Aragón. 6. Conclusión. 7. Bibliografía. 8. Webgrafía.

1 Universidad de Zaragoza (España).

E-mail: cgomez@unizar.es

2 Universidad de Zaragoza (España).

E-mail: dvalero@unizar.es 
Cómo citar: Gomez Bahillo, C., Valero Errazu, D. (2017), Solidaridad y religión. La acción social en las confesiones minoritarias en España. El caso de Aragón, en 'Ilu. Revista de Ciencias de las Religiones 22, 173-202.

\section{Planteamiento}

En la Antigüedad la solidaridad se consideraba como una virtud y se le daba un matiz de carácter religioso. En los prolegómenos de la Revolución Francesa adquiere una dimensión más reivindicativa, de lucha por el reconocimiento de derechos políticos y sociales vinculados a la ciudadanía, y la solidaridad se convierte en un valor común que se materializa en la lucha por la defensa de una sociedad más igualitaria y justa. A lo largo del todo el siglo XIX, la solidaridad aparece relacionada con los movimientos obreros que luchaban contra el modelo de producción capitalista.

Durante la primera mitad del siglo XX, las ideas promovidas por la II Internacional producen sentimientos solidarios entre los componentes de las clases trabajadoras. Tras la Segunda Guerra Mundial, los movimientos solidarios contribuyeron al nacimiento y consolidación del Estado de Bienestar y al desarrollo de las políticas sociales expansivas, y el estado se hace garante de las necesidades de los ciudadanos. Durante el último tercio del siglo XX, el desarrollo de la economía globalizada contribuyó a la destrucción del modelo solidario que había supuesto el estado de bienestar. Y frente a ello, comienzan a surgir de forma espontánea movimientos sociales que promueven una visión comunitaria, y toman la iniciativa en la denuncia de situaciones sociales exclusoras, promoviendo posicionamientos solidarios colectivos.

En la actualidad, la red de apoyo familiar, los movimientos sociales y vecinales, las organizaciones no gubernamentales, asociaciones altruistas, algunas de ellas vinculadas a confesiones religiosas, y las mismas iglesias, lugares de oración y mezquitas están desempeñando una importante función de denuncia de situaciones injustas, y promueven otro modelo de desarrollo y de crecimiento basado en la solidaridad humana ${ }^{3}$.

La solidaridad es el fundamento del mensaje religioso, común a la mayor parte de las religiones monoteístas. La creencia en un Dios bondadoso, justo, equitativo, que permite la desigualdad entre los hombres para dar la oportunidad a los creyentes de ejercitar la misericordia.

En España, la Iglesia Católica ha tenido y tiene un papel histórico en el desarrollo de la acción y asistencia social, a través de sus propias instituciones, entre las que habría que destacar Cáritas, y otras de carácter confesional vinculadas a la organizaciones religiosas, centros sociales y asistenciales, educativos, etc. Durante estas últimas décadas, principalmente a partir de los procesos migratorios que se han producido hacia la sociedad española, están apareciendo otras organizaciones vinculadas a confesiones minoritarias, que realizan una importante acción social, de carácter asistencial y de ayuda, para favorecer la integración e inserción de las personas procedentes de otros países, y de los autóctonos que se encuentran en riesgo de exclusión y marginación social. Y gracias a esta solidaridad, los efectos de la pobreza no son tan intensos en las fases recesivas del ciclo económico en la que la destrucción de empleo y la caída de la productividad lleva a multitud de personas,

García, 2002; González, 2002. 
menos competitivas desde el punto de vista económico, a una situación de riesgo de exclusión social.

Casi todas las confesiones establecidas en España han aumentado su número de creyentes durante las tres o cuatro últimas décadas debido a conversiones por parte de la población autóctona -como por ejemplo la Iglesia Evangélica Española, adventistas, budismo, musulmanes, etc.- o por nuevos asentamientos de población procedentes de otros países, que han contribuido al incremento de comunidades islámicas, denominaciones evangélicas, Iglesia ortodoxa, etc.

Los extranjeros en España suponen, en 2016, el 9,51\% de la población española, y proceden principalmente de Europa y países latinoamericanos. Los nuevos asentamientos de población justifican el crecimiento de la Iglesia Ortodoxa (Rumanía, Bulgaria, Ucrania, Rusia, etc.), de la Comunidad Musulmana (Magreb y África subsahariana, etc.), denominaciones evangélicas -especialmente Iglesias Pentecostales y Carismáticas- (Ecuador, Colombia, Bolivia, etc.), de la Iglesia de Jesucristo de los Santos de los Últimos Días, Comunidad Anglicana y Luteranos (Reino Unido y Alemania), etc.

Tabla 1. Población residente en España, 2016

\begin{tabular}{|l|r|}
\hline Población residente & 46.438 .422 \\
\hline Población extranjera & 4.418 .898 \\
\hline Rumanía & 699.502 \\
\hline Marruecos & 678.467 \\
\hline Reino Unido & 297.000 \\
\hline Italia & 192.053 \\
\hline China & 171.508 \\
\hline Ecuador & 158.967 \\
\hline Alemania & 142.316 \\
\hline Colombia & 135.954 \\
\hline Bulgaria & 130.506 \\
\hline Portugal & 102.318 \\
\hline Francia & 101.336 \\
\hline Ucrania & 90.530 \\
\hline Bolivia & 89.115 \\
\hline Argentina & 71.062 \\
\hline Rusia & 69.454 \\
\hline Otros países & 1.288 .810 \\
\hline
\end{tabular}

INE. Cifras de Población a 1 de enero 2016. Datos provisionales 
En este artículo se reflexiona sobre la función solidaria de las confesiones minoritarias desde la perspectiva de sus creyentes, mediante el análisis de documentos y la voz y vivencias de los propios protagonistas, mediante entrevistas semiestructuradas a representantes responsables de las comunidades y usuarios que manifiestan a través de sus palabras el apoyo y ayuda solidaria que proporcionan o han recibido de su comunidad en algunos momentos, y cómo la solidaridad constituye la base de su compromiso como creyentes.

La expansión de estas confesiones a nivel nacional y en Aragón se refleja en la tabla 2 .

Tabla 2. Locales de culto de Confesiones Minoritarias

\begin{tabular}{|l|c|c|}
\hline Confesión & España & Aragón \\
\hline Federación de Entidades Religiosas Evangélicas de España & 3.751 & 112 \\
\hline Comisión Islámica de España & 1.532 & 67 \\
\hline Testigos Cristianos de Jehová & 638 & 18 \\
\hline Iglesia Ortodoxa & 196 & 11 \\
\hline Federación de Comunidades Budistas & 159 & 6 \\
\hline Cristianos Adventistas del Séptimo Día & 153 & 11 \\
\hline Iglesia de Jesucristo de los Santos de loa Últimos Días & 117 & 1 \\
\hline Comunidad Anglicana & 56 & 1 \\
\hline Otras confesiones cristianas & 50 & 1 \\
\hline Bahá'is & 44 & 1 \\
\hline Federación Comunidades Judías de España & 36 & \\
\hline Otras religiones & 29 & \\
\hline Hinduistas & 22 & \\
\hline Sijs & 20 & \\
\hline Cienciología & 15 & \\
\hline Ciencias cristianas & 7 & \\
\hline
\end{tabular}

Observatorio del Pluralismo Religioso en España, 2016

La Federación de Entidades Religiosas Evangélicas de España (FEREDE), Federación de Comunidades Judías de España (FCJE) y la Comisión Islámica de España (CIE) participan habitualmente en la convocatoria de la Fundación Pluralismo y Convivencia (Ministerio de Justicia) para desarrollar programas relacionados con el fortalecimiento institucional, coordinación de las Federaciones con sus comuni- 
dades religiosas, y mejora y mantenimiento de infraestructuras y equipamiento. En los últimos años han recibido las cuantías ${ }^{4}$ que se reflejan en la Tabla 3.

Tabla 3. Ayudas recibidas por las Federaciones Confesionales Minoritarias (euros)

\begin{tabular}{|l|c|c|c|c|c|c|}
\cline { 2 - 7 } \multicolumn{1}{c|}{} & $\mathbf{2 0 1 1}$ & $\mathbf{2 0 1 2}$ & $\mathbf{2 0 1 3}$ & $\mathbf{2 0 1 4}$ & $\mathbf{2 0 1 5}$ & $\mathbf{2 0 1 7}$ \\
\hline FEREDE & $722.754,31$ & 500.000 & $382.429,18$ & $350.483,43$ & $344.241,32$ & 356.800 \\
\hline FCJE & $329.754,8$ & 215.000 & 169.133 & 163.785 & $163.785,02$ & $169.362,83$ \\
\hline CIE & 592.325 & 300.000 & $395.311,55$ & 219.500 & 229.500 & 255.000 \\
\hline
\end{tabular}

http://www.pluralismoyconvivencia.es/ayudas/linea_1/index.html

Las confesiones minoritarias no reciben ninguna ayuda/subvención económica por parte del Estado, como sucede con la Iglesia Católica. El mantenimiento del clero, compra/alquileres de locales y el desarrollo de cualquier tipo de actividad religiosa son financiadas por la propia comunidad, o por ayudas exteriores procedentes de otros países. La mayor parte de estas comunidades constituyen asociaciones no religiosas, con fines sociales, y a través de ellas participan en convocatorias públicas para proyectos y actividades sociales, educativas, culturales y recreativas.

La Fundación Pluralismo y Convivencia realiza una convocatoria pública para proyectos de carácter cultural, educativo y de integración social, y para mejora y mantenimiento de infraestructuras y equipamiento por parte de las entidades, comunidades religiosas y lugares de culto pertenecientes a confesiones religiosas minoritarias con Acuerdo de cooperación con el Estado español ${ }^{5}$, y que además estén inscritas en el Registro de Entidades Religiosas del Ministerio de Justicia, o hayan pedido su inscripción en el mencionado Registro y estén pendientes de su inscripción definitiva. El grado de participación en la misma es elevado ${ }^{6}$.

\section{Metodología}

La muestra confesional seleccionada para este estudio está compuesta por representantes de las Federaciones Confesionales que están reconocidas por el Ministerio de Justicia, como entidades de notorio arraigo ${ }^{7}$ : Federación de Entidades Religiosas

4 Dichas ayudas se conceden previa participación en la correspondiente convocatoria pública. Ver Convocatorias y Acuerdos de Resolución (Página web: http://www.pluralismoyconvivencia.es/ayudas/linea_1/index.html

5 A dicha convocatoria también pueden presentarse entidades, comunidades religiosas y lugares de culto, que aunque no pertenezcan a una Federación con Acuerdo de Cooperación, cuenten con el aval de alguna de ellas.

6 Ver Convocatorias y Resoluciones de las concesiones otorgadas en la página web: http://www.pluralismoyconvivencia.es/ayudas/linea_2/index.html

7 Real Decreto 593/2015, de 3 de julio, regula la declaración de notorio arraigo de las confesiones religiosas en España. Los requisitos que la confesión ha de reunir son los siguientes:

- «Llevar inscrita en el Registro de Entidades Religiosas treinta años, salvo que la entidad acredite un reconocimiento en el extranjero de, al menos, sesenta años de antigüedad y lleve inscrita en el citado Registro durante un periodo de quince años.

- Presencia en, al menos, diez Comunidades Autónomas y/o Ciudades de Ceuta y Melilla.

- Cien inscripciones o anotaciones en el Registro de Entidades Religiosas, entre entes inscribibles y lugares 
Evangélicas de España (FEREDE) (1992), Federación de Comunidades Judías de España (FCJE) (1992) y Comisión Islámica de España (CIE) (1992). Este reconocimiento se amplía en 2003 a la Iglesia de Jesucristo de los Santos de los Últimos Días (mormones); en 2007 a los Testigos Cristianos de Jehová; y en 2007 a la Federación de Comunidades Budistas de España. La Iglesia Adventista para estos efectos se incluye dentro de la Federación de Entidades Religiosas Evangélicas de España (FEREDE). Consideramos también a la Iglesia Ortodoxa, que se encuentra en pleno proceso de crecimiento a causa de los asentamientos de oriundos de países del este, especialmente de Rumanía, que se están produciendo durante estas dos últimas décadas.

El análisis cualitativo se ha centrado en la comunidad autónoma de Aragón, pero los resultados pueden hacerse extrapolables al resto del país, dado el carácter universal de la acción social de dichas confesiones minoritarias y la similitud del perfil de creyentes y sus necesidades, independientemente de donde tengan ubicada su residencia. Estas confesiones minoritarias tienen proporcionalmente un impacto territorial en Aragón similar al de España (ver Tabla 1), por lo que los informantes seleccionados representan un perfil general. Los inmigrantes suponen el 9,9\% de la población residente, porcentaje un poco superior al medio del país $(9,5 \%)$ y la procedencia de estos asentamientos resulta proporcionalmente bastante similar.

Tabla 4. Población residente en Aragón, 2016

\begin{tabular}{|l|r|}
\hline Población residente & 1.308 .563 \\
\hline Población extranjera & 132.813 \\
\hline Unión Europa & 64.045 \\
\hline Resto Europa & 3,758 \\
\hline África & 35.297 \\
\hline America Norte & 788 \\
\hline Iberoamérica & 21.745 \\
\hline Asia & 7.353 \\
\hline Oceanía & 71 \\
\hline Apátridas & 26 \\
\hline
\end{tabular}

Instituto Aragonés de Estadística. Población y Hogares 2016.

de culto, o un número inferior cuando se trate de entidades o lugares de culto de especial relevancia por su actividad y número de miembros.

- Estructura y representación adecuada y suficiente para su organización a los efectos de la declaración de notorio arraigo.

- Presencia y participación activa en la sociedad española».

La Iglesia Ortodoxa Española, perteneciente a la diócesis de Europa Occidental del Patriarcado de Serbia, colabora con la FEREDE para llegar a acuerdos conjuntos con el Gobierno de España, Gobiernos autonómicos y demás instituciones. Todavía no tiene el reconocimiento por parte del Estado como confesión con notorio arraigo. 
Se ha seleccionado a informantes de las confesiones que desarrollan una acción social pública y que disponen de instituciones específicas para ello, y de la que se pueden beneficiar cualquier persona necesitada, independientemente de su credo religioso.

Los Cristianos Testigos de Jehová, Budistas, Mormones y Judíos no desarrollan una acción social directa y visible, con carácter institucional, y lo hacen a título privado, y sin trascendencia pública, por ello no se ha recurrido a informantes de estas confesiones.

\section{Fundamentación teórica y precisión conceptual}

Desde diferentes perspectivas podemos acercarnos al concepto de solidaridad, si bien en este trabajo vamos a hacerlo desde la filosofía social, la teoría sociológica y la sociología de la religión para establecer las bases teóricas que nos ayuden a comprender la acción solidaria que las confesiones religiosas están realizando en la sociedad actual.

El humanismo promueve el «amor universal y solidario» entre todos los seres humanos, y condena la acumulación de bienes por parte de unos pocos a consta de la carencia o insuficiencia de recursos de una gran mayoría.

La perspectiva filosófico-antropológica concibe la solidaridad a partir de la relación humana, y la obligación moral y compromiso de cada uno con los demás. Y esta predisposición hacia la solidaridad ha sido asumida por nuestra cultura judeo cristiana, y constituye un principio de comportamiento moral, que $\mathrm{Kant}^{8}$ ha definido como «imperativo categórico», que determina la actitud y la conducta de la persona:

Obra de tal modo que la máxima de tu voluntad siempre pueda valer al mismo tiempo como principio de una legislación universal. La solidaridad consiste en hacer el bien, es decir, ayudar a otros hombres necesitados de ser felices, según las propias capacidades, y sin esperar nada a cambio, es un deber de todo hombre, y es la máxima del interés común?.

Ser solidario es para Kant, algo inherente a la persona humana, y se fundamenta en esa obligación moral de apoyar y ayudar a los que tienen dificultades para integrarse en la sociedad y disfrutar de bienestar y seguridad colectiva.

Desde el punto de vista filosófico, la solidaridad es la manera como se organiza política y socialmente un grupo, la sociedad, la ciudad, el país, para conseguir mayores niveles de bienestar político, social y económico para toda la población. La solidaridad es necesaria para el buen funcionamiento de la sociedad y para que ésta pueda progresar mediante el reconocimiento de derechos y obligaciones para todos los ciudadanos. Por ello, ser solidario supone rebelarse contra las injusticias y desigualdades sociales y proponer alternativas para todos, pero especialmente para los que son víctimas de situaciones de exclusión o incluso marginación que ellos no han generado. 
La solidaridad va más allá de la ayuda material, y supone un posicionamiento en la defensa de la dignidad de la persona, de sus derechos, por encima de la raza, etnia, género, inclinación sexual, ideología, posición social, creencias religiosas, etc. La verdadera solidaridad se fundamenta en una concepción universal basada en el derecho de todos a la igualdad de oportunidades ${ }^{10}$. Y esto es lo que ha llevado a la formación y constitución de multitud de grupos, asociaciones y organizaciones cuyo objetivo e ideario es el reconocimiento de los derechos universales y la atención a las necesidades que se producen cuando éstos se vulneran.

La perspectiva sociológica se centra en la dimensión social de la persona (Aristóteles) y en su necesidad de vivir en comunidad. La idea de solidaridad aparece entre los socialistas utópicos como respuesta a los problemas y situaciones de desigualdad y exclusión generadas a partir del nacimiento y desarrollo del capitalismo. El socialismo promueve la solidaridad para lograr la igualdad universal entre los hombres y la desaparición de las diferencias sociales que se producen por la distribución desigual de la propiedad y de la riqueza. Henri de Saint-Simón ${ }^{11}$ propone la solidaridad social y la organización racional de la producción para conseguir un capitalismo equitativo, con una planificación que permita superar la pobreza. Charles Fourier ${ }^{12}$ promueve un sistema de organización social -falansterio- para conseguir una sociedad ideal donde todos los hombres sean libres, tanto desde el punto de vista económico y legal como cultural.

Rousseau $^{13}$ se refiere al estado natural del hombre como una situación idónea para vivir en libertad y sin servidumbres, y muestra cómo la sociedad capitalista -a causa de la división social del trabajo y la consolidación de los derechos de propiedad privada de los bienes de producción- es el origen de la desigualdad entre los hombres y la causa del conflicto social -postulado que será tomado posteriormente por Marx $^{14}$, que lo desarrollará en El Capital-. Y propone como alternativa un pacto o acuerdo basado en el reconocimiento de deberes, derechos y obligaciones comunes a todos. La igualdad es el fundamento del contrato y permite el establecimiento de una voluntad general, que defiende los intereses colectivos, y es el fundamento de la vida social. Rousseau ${ }^{15}$ insiste nuevamente en estos aspectos y presenta un modelo social de igualdad basado en la solidaridad y compromiso mutuo, que son el origen de la fraternidad humana. La fraternidad es sinónimo de hermandad, y adquiere un significado especial a finales del siglo XVIII, al ser una de las tres premisas de la Revolución Francesa, y se convierte en uno de los fundamentos del estado democrático. A partir del siglo XIX se comienza a utilizar el concepto de solidaridad para denominar las relaciones fraternales entre los hombres.

Durkheim $^{16}$ entiende la solidaridad como la capacidad de entregarse a otros, considerándolos como semejantes, y compartir con ellos sentimientos, necesidades materiales, etc. Todo ello forma parte de la conciencia colectiva, que es necesaria para el desarrollo y funcionamiento de los grupos sociales. La vida social es posible por los lazos de solidaridad existentes entre los hombres, que crean una conciencia

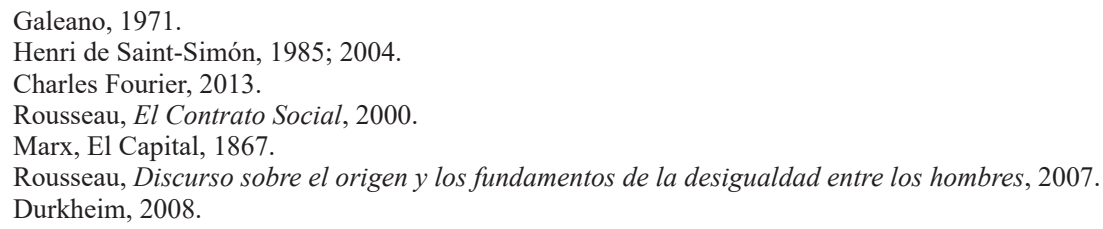


colectiva que hace posible la cohesión social, que es la que permite la formación y funcionamiento de las organizaciones sociales. Javier de Lucas ${ }^{17}$ ha profundizado en este concepto, y considera que la concepción durkheniana es ambigua ya que es concebida como una categoría científica, es decir, como un hecho social y un recurso ideológico. Y a partir de esta doble concepción construye su teoría de la evolución social: solidaridad mecánica y solidaridad orgánica. La primera de ellas tiene una dimensión religiosa, y la integración se produce a través de la identificación, mientras que la solidaridad orgánica se concibe como una idea moral, un instrumento de legitimación en el que subyace un componente ideológico.

A partir de la segunda mitad del siglo XX, el concepto de solidaridad aparece unido a contextos reivindicativos, en los que diferentes colectivos se apoyan mutuamente para presionar y conseguir sus exigencias y demandas, principalmente de carácter socioeconómico, por lo que los movimientos solidarios aparecen más cercanos a grupos y tendencias políticas y sindicales próximas a la izquierda.

Los movimientos sociales han supuesto una organización popular de solidaridad que conduce al robustecimiento de la Sociedad civil, actuando como contrapoderes al poder político y económico hegemónico, conllevando a un fortalecimiento y extensión de los lazos existentes dentro de la comunidad ${ }^{18}$.

Los movimientos solidarios aparecen frecuentemente ante situaciones de injusticia y desigualdad social. La solidaridad es en definitiva uno de los pilares sobre los que se debería asentar la sociedad, y que hizo posible la constitución y desarrollo del estado de bienestar de las décadas pasadas; y cuando este principio y virtud ética se arrincona entra también en crisis el modelo social igualitario y redistributivo. Por tanto, «ser solidarios» es una actitud ante la vida, que consiste en pensar en el otro y en el conjunto de la colectividad, y hacer de ello la guía del comportamiento y de la conducta.

La solidaridad es, por tanto, una inclinación natural de la persona que se produce al margen de las creencias religiosas, pero que se desarrolla en la mayoría de las confesiones, y forma parte de la manera de obrar y actuar de sus creyentes. Dentro del agnosticismo y ateísmo también existen personas y grupos solidarios en la defensa de los intereses colectivos. No obstante, se ha relacionado histórica y socialmente esta actitud y disponibilidad solidaria de las personas con creencias y compromisos religiosos y, en la mayoría de las ocasiones, se ha asociado a la compasión, entendida ésta como una predisposición y sensibilidad hacia los sufrimientos y necesidades de los demás. De ahí que desde las confesiones religiosas hayan surgidos multitud de grupos solidarios y altruistas sensibles a las necesidades de los que tienen problemas para su inserción e inclusión social.

La religión promueve una actitud de servicio, de entrega, de amor universal hacia los demás, y genera entre sus fieles una sensibilidad especial hacia las necesidades de los otros, cuando se ven privados de sus derechos. Todas las confesiones religiosas han favorecido siempre la solidaridad no sólo entre su propio grupo de creyentes sino con un carácter universal. Por lo que la solidaridad entre los creyentes tiene una dimensión humanística, moral, social y política, de carácter universal.

Javier de Lucas, 1993.

Alaminos, 2014: 51. 
La sociología explica la función que la religión ha tenido a largo de la historia de la humanidad como instrumento de integración e inserción social, a través de la cual se facilita el consenso y concordia entre los grupos sociales. Durkheim ${ }^{19}$ consideraba que en las sociedades prehistóricas la religión poseía una fuerza integradora, a través del cumplimiento de un conjunto de normas y prescripciones que servían para la identificación de cada uno de los miembros con su grupo (clan, aldea, pueblo, etc.), y estabilizadora al definir los roles y status de cada grupo social: mujeres, hombres, súbditos y gobernantes.

Weber ${ }^{20}$ reflexiona sobre el papel que la religión tiene en la sociedad, la estrecha relación existente entre la ética calvinista y el desarrollo del capitalismo, y cómo las creencias religiosas determinan las formas de comportamiento y de relación humana. Existen distintas religiones porque responden a contextos económicos y sociales diferentes, y cada religión ha desarrollado estrategias para ayudar a los que las profesan a adaptarse al entorno ${ }^{21}$. La religión tiene una función social y asistencial en la manera que promueve un espíritu de fraternidad a través de valores de solidaridad, justicia social, paz, etc., y, a través de ellos, generar la hermandad entre los hombres, especialmente con aquellos que la misma sociedad excluye. Weber ${ }^{22}$ introduce el concepto de ética religiosa de hermandad para explicar esta dimensión social de la religión y el comportamiento solidario intra y extragrupo, basado en la reciprocidad mutua y en la obligación de dar apoyo a los necesitados, formando una confraternidad entre todos.

Parsons $\mathrm{s}^{23}$ plantea el poder que tienen las ideas religiosas para facilitar la integración y la cohesión social, y orientar el comportamiento de los hombres. La religión cumple una función de compensación y contribuye a hacer la vida más agradable a los creyentes, en la manera que aceptan su situación social y mantienen una vivencia de esperanza en la justicia del más allá. Según Horkheimer ${ }^{24}$, la religión tiene aspectos útiles para la convivencia humana ya que mantiene la esperanza en un mundo mejor y más justo en el que todos los hombres serán iguales.

Hasta fechas recientes, la religión constituía, y actualmente todavía constituye en algunos países, un instrumento de cohesión y de integración social que proporciona una cierta estabilidad política y social, como ha estudiado Berger ${ }^{25}$. No podemos olvidar que en la unicidad de la religión se han fundamentado algunos regímenes totalitarios, como el caso de España fue el nacionalcatolicismo durante la dictadura franquista.

La nueva realidad religiosa de nuestras ciudades y pueblos nos enseña que en todas las religiones, y en el mismo laicismo, encontramos personas con una gran sensibilidad social y humana, y que ello no es patrimonio de una única religión, y ni siquiera de la misma religión. Por solidaridad algunos líderes religiosos mantuvieron una posición de denuncia frente a la violación de los derechos humanos, principalmente de los excluidos a causa de la globalización neoliberal, y de todas las personas y colectivos que son marginados por razones de género, religión, etnia,

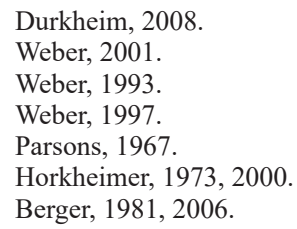


raza y cultura, y trabajaron a favor de la justicia social. Dentro del cristianismo destacaríamos, por su impacto mundial, las posiciones de denuncia de Martin Luther King, Desmond Tutu -arzobispo anglicano de África del Sur-, monseñor Oscar A. Romero, Ignacio Ellacuría, Teresa de Calcuta, etc. En el islam hay numerosos movimientos y líderes religiosos comprometidos con la defensa de los derechos humanos, como el iraní Alí Shariati (1933-1977), Mohamed Jatami, presidente de la República Islámica de Irán, (1997-2005), la científica social marroquí Fátima Mernissi, la jueza iraní Shirin Ebadi, premio Príncipe de Asturias y Premio Nobel de la Paz 2003, el indio Asghar Ali Engineer, etc. En el hinduismo, Gandhi (1869-1948) defendió los derechos humanos a través de la resistencia cívica y la no violencia activa en el deber y en la fe; Bhirmao R. Amdedkar (1859-1951) luchó contra la exclusión social, la marginación religiosa y la discriminación política de los intocables. En el budismo, el Dalai Lama es un referente mundial en la lucha por la paz y la defensa de los derechos humanos.

La solidaridad debe ser el fundamento de las políticas igualitarias, a partir de las cuales se acuerden estrategias y desarrollen acciones para conseguir que todos los ciudadanos tengan los mismos derechos. Ello supone una respuesta colectiva desde las instituciones públicas para institucionalizar la solidaridad a través de políticas públicas comunes ${ }^{26}$, fundamentadas en la capacidad emancipadora que supone el reconocimiento de los derechos humanos como principio rector de las políticas internacionales ${ }^{27}$. Y desde la perspectiva de los derechos humanos se debe dar respuesta adecuada a la crisis migratoria que estamos viviendo durante estas últimas décadas ${ }^{28}$.

La solidaridad aparece, por tanto, vinculada a la acción comunitaria, a lo colectivo, a la justicia, a la lucha contra la desigualdad, exclusión y marginación social, y está asociada al compromiso ético y político que trascienden los sentimientos de compasión y de mera caridad. La solidaridad es una actitud, una predisposición de la persona a obrar y actuar de acuerdo a unos principios, y tiene como finalidad conseguir el bienestar de todos los seres humanos, próximos o lejanos, reducir las diferencias sociales y contribuir al reparto equitativo de la riqueza. El compromiso social supone pasar de la solidaridad como sentimiento puntual a la solidaridad como actitud permanente ${ }^{29}$. La educación en valores solidarios permitirá, sin duda, consolidar una sociedad más democrática y participativa, formada por ciudadanos responsables y comprometidos con la justicia social ${ }^{30}$.

\section{Institucionalización de la solidaridad en las confesiones minoritarias}

La mayoría de las confesiones minoritarias han asumido este compromiso social y sus creyentes viven su fe a través de una actitud solidaria. Atender a personas necesitadas constituye un imperativo para cualquier creyente, y en especial a los que forman parte de la propia comunidad. El impacto y repercusión de sus actividades sociales y culturales son diferentes entre unas confesiones y otras.

\footnotetext{
De Lucas, J., 2000a: 72.

De Lucas, J., 2000b: 21.

De Lucas, J., 1993: 91.

Campo, 1996: 163.

Carrero, 2013.
} 
Buades y Vidal ${ }^{31}$ proponen una tipología general y aproximativa de las actividades desarrolladas por las distintas confesiones en la Comunidad Valenciana, pero que se repite también y es similar en otras comunidades autónomas, como puede comprobarse en los diferentes estudios realizados desde la Fundación Pluralismo y Convivencia $^{32}$.

Cuadro 1. Tipología de actividades de las confesiones minoritarias

\begin{tabular}{|c|c|c|}
\hline Modelo & Actividad & Confesiones \\
\hline Intensivo & $\begin{array}{l}\text { - Intensa actividad religiosa } \\
\text { comunitaria } \\
\text { - Fuerte atención social } \\
\text { - Gran proyección cultural pública }\end{array}$ & $\begin{array}{l}\text { - Iglesias Pentecostales independientes } \\
\text { - Algunas Iglesias Pentecostales y } \\
\text { Bautistas } \\
\text { - Algunas comunidades islámicas }\end{array}$ \\
\hline Dual & $\begin{array}{l}\text { - Intensa actividad celebrativa } \\
\text { comunitaria } \\
\text { - Baja proyección cultural } \\
\text { - Actividad social a través de } \\
\text { ONG }\end{array}$ & $\begin{array}{l}\text { - Iglesias Bautistas y Asambleas de } \\
\text { Hermanos } \\
\text { - Comunidades islámicas a pesar de } \\
\text { que la acción social se realiza desde la } \\
\text { mezquita. }\end{array}$ \\
\hline Proyectivo & $\begin{array}{l}\text { - Actividad religiosa moderada } \\
\text { - Visible proyección cultural } \\
\text { - Actividad social formal }\end{array}$ & $\begin{array}{l}\text { - Iglesia Ortodoxa } \\
\text { - Comunidad Anglicana } \\
\text { - Comunidad Judía, a pesar de no tener } \\
\text { una actividad social formal } \\
\text { - Comunidad Hindú (proyección social y } \\
\text { cultural) }\end{array}$ \\
\hline Activo & $\begin{array}{l}\text { - Actividad religiosa intensa } \\
\text { - Actividades culturales públicas } \\
\text { - Acción social desde la Iglesia o a } \\
\text { través de ONG }\end{array}$ & $\begin{array}{l}\text { - Iglesia Adventista } \\
\text { - Ejército de Salvación } \\
\text { - Asambleas de Dios }\end{array}$ \\
\hline Internista & $\begin{array}{l}\text { - Intensa actividad religiosa } \\
\text { comunitaria } \\
\text { - Reducida proyección social y } \\
\text { acción social }\end{array}$ & $\begin{array}{l}\text { - Evangélicos independientes } \\
\text { Iglesias de Filadelfia } \\
\text { - Mormones } \\
\text { - Testigos de Jehová }\end{array}$ \\
\hline Esporádico & $\begin{array}{l}\text { - Celebraciones de baja frecuencia } \\
\text { - Actividades culturales } \\
\text { moderadas abiertas }\end{array}$ & $\begin{array}{l}\text { - Budistas } \\
\text { - Vaisnavas } \\
\text { - Sikhs } \\
\text { - Bahá'is }\end{array}$ \\
\hline
\end{tabular}

Buades y Vidal (2007). Minorías de lo mayor, 99-100

31 Buades y Vidal, 2007.

32 Estudios patrocinados por la Fundación Pluralismo y Convivencia, publicados por la Editorial Icaria, en la Colección Pluralismo y Convivencia: Buades 2006; Buades et alt. 2007; Briones 2010; Briones el alt. 2013; Diez de Velasco 2008; Estruch et alt. 2007; Gómez Bahillo el alt. 2009; López García et alt. 2007; Hernando de Larramendi et alt. 2009; Izquierdo et alt. 20014; Lasheras 2012; Montes del Castillo et alt. 2011; Ruiz et alt. 2010; Valero el alt. 2012. 
A continuación analizamos la red de ayuda social de las principales confesiones minoritarias ubicadas en España, tras el análisis documental de sus informes y publicaciones, muchos de los cuales aparecen en la web institucional de la respectiva confesión.

\section{Iglesia Evangélica}

La Reforma Protestante, de la que actualmente se celebra el 500 aniversario, contribuyó a la aparición de diferentes denominaciones cristianas a lo largo de Europa, durante los siglos XVI y XVII, como los luteranos, calvinistas (reformados o presbiterianos), congregacionalistas, anglicanos o metodistas. Posteriormente, y en especial desde el siglo XIX en Estados Unidos, surgen nuevas formas de cristianismo evangélico independientes, como las iglesias bautistas y pentecostales y el movimiento carismático, que termina extendiéndose por Europa, y durante la segunda mitad del siglo XX también por España, y actualmente aglutinan a más de un tercio de los evangélicos del mundo.

Los orígenes de la presencia evangélica contemporánea en España hay que situarla en 1835, cuando llega la primera misión evangelizadora enviada por la Sociedad Bíblica Británica y Extranjera, y a pesar de los impedimentos y represión gubernativa y de la reacción de la iglesia católica consigue formar pequeñas comunidades de creyentes que se ven obligados a vivir en la clandestinidad, según el momento político. La posibilidad de expansión del protestantismo va a tener un desarrollo paralelo al de la evolución política española. Desde entonces han existido comunidades evangélicas, algunas de las cuales perduran desde entonces, como el caso de la Iglesia Evangélica Española. A lo largo de la primera mitad del siglo XX, empiezan a establecerse otras denominaciones como la Iglesia Bautista, Asamblea de Hermanos, Alianza Evangélica Española, etc.

El número de evangélicos en España es destacado y se aproxima a 1,5 millones, y está en crecimiento por las conversiones de la población autóctona como por la población que se ha asentado o pasan largos periodos en Baleares, Canarias y costa mediterránea. Las provincias de Barcelona, Valencia y Málaga son las que más lugares de culto tienen de esta confesión.

Durante las últimas décadas, los asentamientos de inmigrantes latinoamericanos han contribuido al establecimiento de iglesias pentecostales y carismáticas como la Iglesia Evangélica Pentecostal, Iglesia Pentecostal de Betel, Iglesia Evangélica de Filadelfia, etc. En estas comunidades se acoge, apoya y ayuda a los recién llegados, y a los que estando ya asentados lo precisan, para buscar trabajo, alojamiento, relaciones sociales, etc. de manera que los lugares de oración y culto se convierten en referencia para muchos de ellos.

La mayor parte de estas denominaciones forman parte de la Federación de Entidades Religiosas Evangélicas de España (FEREDE) y con anterioridad de la Comisión de Defensa Evangélica, constituida en mayo de 1956, para la defensa del colectivo evangélico español, y que desempeñó una importante función hasta 1982, en que se inician conversaciones para la firma de un convenio de Cooperación entre el Estado y la confesión protestante. La administración requirió que fuera un único interlocutor evangélico por lo que en febrero 1986 se constituye FEREDE, que asume la representación de las confesiones protestantes, a estos efectos. La Federación ha mantenido un compromiso solidario de denuncia de la desigualdad, injusticia y vul- 
neración de los derechos humanos, y se ha vinculado a los movimientos y plataforma sociales

La acción social directa es importante, y en estos momentos las diferentes denominaciones destinan una parte importante de sus recursos económicos a los más desfavorecidos, entre los que hay que incluir a un sector cuantitativamente importante de población inmigrante, y dedican algunos espacios de sus iglesias y lugares de culto a la atención asistencial directa como reparto de ropa, comida, etc. Para ello, muchas confesiones han creado sus propias asociaciones de carácter social y a través de ellas realizan su acción social y otras actividades sociales y culturales. Al ser elevado su número, no hacemos referencia a cada una de ellas, y consideramos exclusivamente las que tienen un campo de acción más amplio, y que abarca a todo el estado o a varias comunidades autónomas ${ }^{33}$.

Diaconía, Entidad Religiosa Asociativa, creada en 1997 por FEREDE, es una plataforma para coordinar la intervención de las distintas iglesias evangélicas y entidades que ayudan a los colectivos vulnerables. Dispone de una importante red solidaria a nivel nacional, de la que dependen las redes territoriales (entidades que trabajan dentro de una comunidad autónoma) y redes por colectivos y áreas con un ámbito de actuación nacional. De ella dependen más de 80 entidades de carácter menor que desarrollan programas y acciones locales o participan en proyectos colectivos. También asumen proyectos de formación, de atención, gestión y cooperación internacional dirigidos al voluntariado y a otros colectivos.

Diaconía, Inmigración e Interculturalidad, a través del Programa Crisol Network, financiado por la Dirección General de Migraciones del Ministerio de Empleo y Seguridad Social, fortalece las estructuras de las entidades que atienden a la población inmigrante. El Programa Crisol Junior, también financiado por este organismo público, y dirigido a menores de terceros países residentes en España, desarrolla estrategias contra la discriminación y el racismo.

Las acciones que se realizan desde Diaconía, en colaboración con las entidades y servicios sociales de cada comunidad de creyentes están orientadas, entre otras, a:

- Reinserción social de los colectivos con riesgo de exclusión como presos, toxicómanos, enfermos crónicos, desempleados sin recursos, etc. Se dispone de centros especializados en atención a drogodependientes, como Centro Remar $^{34}$ y $R E T O^{35}$, en donde se desarrollan programas de desintoxicación,

33 Los estudios monográficos que han sido realizados por la Fundación Pluralismo y Convivencia en cada Comunidad Autónoma y en las ciudades de Ceuta y Melilla, y que han sido publicados por la editorial ICARIA, en la Colección Pluralismo y Convivencia, recogen la acción social pormenorizada de las distintas asociaciones y entidades confesionales dentro de su espacio territorial.

34 http://www.remar.org/queesremar1.html

En el año 1990 se constituye la Asociación REMAR España y comienzan las actividades en Aragón, Canarias, Navarra y País Valenciano. En 1993 consiguen implantarse en todo el Estado. En el año 2008 está presente en los cinco continentes.

Remar es considerada la acción social de las Iglesias Cuerpo de Cristo y su actividad se centra en drogadicción, ayuda a mujeres maltratadas, programas de atención a la infancia, programa de salud (atención a enfermos terminales), etc

35 La ONG RETO para la Esperanza aparece en Cantabria en 1985, y se ha ido extendiendo por otras ciudades españolas. Es un servicio para ayudar al drogodependiente prestado, en ocasiones, por personas que en su día fueron toxicómanos y que ahora se dedican a trabajar en comunidades terapéuticas. En ellas, se capacita profesionalmente a las personas que por causa de la droga y por carencia de competencias profesionales tienen dificultades de acceso al mercado laboral, capacitándolas en un oficio. Además el trabajo es utilizado como un 
rehabilitación y reinserción sociolaboral y de atención a los internos de las prisiones, a cargo de grupos de voluntarios de las distintas confesiones e iglesias. Existe también un programa de atención sanitaria que consiste en visitar a enfermos hospitalizados y, en especial, a los que no tienen familia próxima.

- Atención de carácter asistencial, se realiza a través de Misión Evangélica Urbana $^{36}$. Un movimiento de acción social para intervenir con personas que están en desventaja social, en pobreza severa, en marginación o exclusión social, proporcionando recursos para atender a las necesidades básicas a través de centros de día para menores y familias. Entre sus objetivos fundacionales, la Federación de Misiones Evangélicas Urbanas tiene previsto:

1.- La reducción de la pobreza en España y preocupación por la pobreza en el mundo. 2.- Trabajos de integración y promoción social de las personas en dificultad social. 3.- Intervenciones en el mundo de la infancia en marginación. 4.Detección de personas en exclusión social orientando nuestra intervención hacia la plena integración social de la persona. 5.- Relaciones interculturales e integración cultural de los inmigrantes. 6.- Programas de búsqueda activa de Empleo. 7.- Estudio de las situaciones sociales marginantes o excluyentes. 8.- Denuncia de las situaciones sociales injustas. 9.- Programas de sensibilización y concienciación de la sociedad en torno a las situaciones sociales marginantes y excluyentes. 10.- Todo tipo de Programas asistenciales que proporcionen a las personas las ayudas sociales básicas para que logren vivir con dignidad ${ }^{37}$

Otro campo de acción social es la atención y asistencia a reclusos con quienes se establece una relación personalizada, transmitiéndoles el apoyo de la comunidad y proporcionando ayuda para cubrir sus necesidades básicas como ropa y calzado, o en los trámites legales, juzgados, abogados o acompañarles para la gestión de documentos. La acción asistencial se hace extensiva a las familias de los presos, en ocasiones rotas y desestructuradas.

Para llevar a cabo las actividades solidarias y de carácter social estas entidades sin ánimo de lucro, suelen acudir a las convocatorias específicas de subvenciones públicas o bien solicitar ayudas a los organismos oficiales e instituciones privadas.

medio para adquirir actitudes y valores como la disciplina, trabajo en equipo y responsabilidad. Su fuente de financiación es el trabajo que realizan la personas que están en la comunidad terapéutica y que consiste en la recogida y posterior venta de ropa, muebles y demás enseres de segunda mano, además de otros ingresos procedentes de reciclajes de residuos sólidos urbanos, de la venta de los productos realizados por ellos en los talleres ocupacionales, y de donaciones de particulares y de empresas.

36 La Misión Evangélica Urbana de Madrid se constituye en el año 1986. Surge como una Entidad Religiosa Asociativa, siendo los miembros fundadores diferentes iglesias del ámbito interdenominacional de la Comunidad de Madrid, que sigue los modelos ya evaluados y experimentados en otras grandes ciudades del mundo.

La Federación de Misiones Evangélicas Urbanas de España, constituida en Madrid el 21 de octubre de 2011, tiene sedes en Madrid, Valencia, Zaragoza, Sevilla y Vigo, y trabaja a través de la red desarrollando proyectos conjuntos entre las distintas sedes.

Estas Misiones se financian con las aportaciones de los creyentes y de las iglesias, y con algunas subvenciones públicas procedentes de la Fundación Pluralismo y Convivencia del Ministerio de Justicia, Ayuntamientos o Comunidades Autónomas. Para proyectos concretos también se recibe, en ocasiones, ayudas de fundaciones privadas laicas, además de Cruz Roja y Banco de Alimentos.

$37 \mathrm{http}: / /$ www.lupaprotestante.com/blog/se-constituye-la-federacion-de-las-misiones-evangelicas-urbanas-de -espana/ 
A nivel internacional, las iglesias evangélicas destinan recursos económicos a proyectos sociales en zonas desfavorecidas: creación y mantenimiento de hospitales, colegios, centros de acogida para mujeres y niños, campos de refugiados, etc.

\section{Iglesia Cristiana Ortodoxa}

La Iglesia Cristina Ortodoxa tiene su origen en las comunidades cristianas de la mitad oriental del Mediterráneo, y surge tras el Cisma de Oriente y Occidente, en 1054. Se organiza en torno a patriarcados, que son autónomos e independientes, y no existe una cabeza central como en la Iglesia Católica.

En España, su presencia está relacionada con la inmigración procedente de países del este europeo como Rumanía, Bulgaria, Rusia, Ucrania, Bielorrusia, etc. Al ser la comunidad rumana numerosa se está produciendo un notable crecimiento de la iglesia ortodoxa rumana y, en menor medida, de otras iglesias ortodoxas. En ocasiones, sus lugares de culto son iglesias católicas, hasta que el grupo de fieles es suficientemente grande para formar su propia iglesia, generalmente en un local alquilado. En la actualidad cuenta con unos 600.000 fieles, y el mayor numero de lugares de culto se encuentran en Madrid, Alicante, Girona, Valencia, Barcelona e Islas Baleares.

El compromiso social de la Iglesia Ortodoxa consiste en la participación y apoyo a muchos movimientos sociales confesionales, principalmente de la iglesia católica y de las comunidades evangélicas, manteniendo una misma postura y posicionamiento respecto a la defensa de los derechos humanos y la denuncia de situaciones injustas y excluyentes.

La Iglesia Ortodoxa, directamente o a través de Asociaciones, atienden a muchos inmigrantes llegados a España procedentes de los países del este europeo, ayudándoles a resolver cuestiones administrativas y a encontrar trabajo, o facilitándoles el viaje de regreso a su país cuando no se cumplen las expectativas con las que vinieron. Desde las parroquias se realiza una acción social relacionada con la inserción social y laboral a través de una red informal que ayuda a la búsqueda de empleo, especialmente en el caso de las mujeres, a encontrar vivienda, proporciona información sobre las ayudas y servicios sociales públicos de la localidad, etc. También hay una actividad de apoyo a las familias en crisis, ayudándoles a resolver problemas de pareja y de relación con los hijos.

\section{Iglesia Cristina Adventista del Séptimo Día}

Los Adventistas del Séptimo Día surgieron en Estados Unidos a principios del siglo XIX. En España, los primeros adventistas llegaron a comienzos del siglo XX. Se incluyen en la Federación de Entidades Religiosas Evangélicas de España (FEREDE), a pesar de que generalmente se les suele clasificar dentro del cristianismo independiente de carácter bíblico.

Los adventistas realizan la acción social a través de la Acción Solidaria Adventista $^{38}$ (ASA) y la Agencia Adventista de Desarrollo y Recursos Asistenciales

38 La Acción Solidaria Adventista (ASA) es un programa que realiza múltiples iniciativas solidarias y de servicios de asistencia social, que realiza las distintas iglesias organizadas, a través de sus líderes y miembros, en favor de los necesitados. Cada Iglesia realiza proyectos y actividades en beneficio de personas y familias necesitadas. 
(ADRA). La Acción Solidaria Adventista (ASA) propone iniciativas solidarias y prestaciones de asistencia social con la iglesia local. La Agencia Adventista de Desarrollo y Recursos Asistenciales (ADRA) es una organización no gubernamental con fines sociales, de beneficencia y filantrópicos. Esta agencia forma parte de la red internacional de organizaciones humanitarias independientes. ADRA se estableció en 1984, tiene presencia en 131 países y ejecuta proyectos de desarrollo comunitario y de asistencia humanitaria dirigidos a la protección de las personas más vulnerables, apoyo a la familia, promoción de la salud, provisión de alimentos y ayuda para mejorar las condiciones de vida de los más necesitados.

En relación con la inmigración, ADRA realiza actividades de formación, dando clases de español para inmigrantes y promoviendo talleres monográficos sobre búsqueda de empleo, atención a personas mayores, hostelería, etc.; desarrolla acciones de mediación con las personas que buscan trabajo y los empleadores; informa sobre los servicios de carácter social que proporcionan otras instituciones, principalmente públicas; ayuda a la tramitación administrativa de permisos, reagrupación familiar y sobre todo lo que está relacionado con la inserción en la sociedad de acogida.

\section{Comunidad islámica}

Durante la Edad Media, el Islam tuvo una gran importancia en la Península Ibérica, y se mantuvo una diversidad religiosa y la convivencia de las tres religiones. Durante siglos fue la religión dominante en el territorio denominado Al Ándalus. Las comunidades musulmanas actuales tienen su origen en los acuerdos de amistad entre España y los Países Árabes (Líbano, Siria, Palestina. Egipto y Jordania) y norte de África (Marruecos), firmados durante los años cincuenta y sesenta del siglo pasado, y que permitieron la entrada en España de jóvenes musulmanes que venían para cursar estudios universitarios, principalmente medicina. Estos universitarios se constituyeron en asociaciones estudiantiles locales como las de Granada, Madrid, Oviedo, Valencia o Zaragoza, y la nacional Unión Estudiantil Musulmana de España. La Asociación Musulmana de España tiene sus orígenes en el contexto de 1967, en que se promulga la primera ley que permite a los musulmanes organizarse en asociaciones confesionales, de ámbito nacional ${ }^{39}$.

Desde el último tercio del siglo pasado, el número de mezquitas y asociaciones y centros culturales islámicos está en constante crecimiento en España. En los años noventa, la mayor parte de ellas pertenecen a alguna de las dos federaciones, la UCIDE (Unión de Comunidades Islámicas de España) y la FEERI (Federación Española de Entidades Religiosas Islámicas), que integraban la Comunidad Islámica de España en esa época. Se han desarrollado nuevas estructuras federativas y de coordinación a nivel de comunidades autónomas generando un panorama caracterizado por su variabilidad y su dinamismo.

En España la comunidad islámica supera, en 2016, los 1,9 millones de fieles debido a la reciente inmigración, en especial la que proviene del norte de África. Existen también minorías de conversos al Islam, algunos de ellos por razón de matrimonio. Las provincias de Barcelona, Madrid, Valencia, Murcia, Alicante e Islas

39 Ley 44/1967, de 28 de junio, regulando el ejercicio del derecho civil a la libertad en materia religiosa (BOE de 1 de julio). 
Baleares son las que tienen un mayor número de mezquitas y centros de oración, que a nivel nacional es de 1.323 .

La solidaridad está muy interiorizada entre los musulmanes. La Shari'ah constituye el tercer pilar del Islam, y la Ley Islámica establece la obligación que tiene el creyente de repartir sus riquezas entre los que carecen de recursos necesarios para sobrevivir. La riqueza es una bendición de Al·lâh, y se recibe con la obligación de repartir entre los necesitados la parte que cada familia no precisa para vivir.

La Shari'ah manda al creyente tener una actitud de solidaridad con los que tienen menos recursos, apoyándoles en sus necesidades materiales y espirituales. Para ello, se establece la $z a k a t^{40}$ o limosna que sirve para agradecer los dones recibidos a Al·lâh, mediante la redistribución de una parte de ellos entre los necesitados. Esta obligación no exime al creyente de la donación de limosnas con carácter voluntario, la sadaqa.

La zakat no es sinónimo de caridad, ya que dar limosna en el Islam no es algo que dependa de la bondad personal sino que es algo impuesto por el Profeta y que aparece en el Corán, dado que los que carecen de bienes tienen el mismo derecho a disfrutarlos que los que los tienen en exceso. Hay que tener presente que «ser pobre» entre los musulmanes no tiene una dimensión peyorativa sino que lo son aquellos que han tenido mala fortuna, pero sin que ello suponga ningún estigma para su persona. La manera de hacer efectiva la zakat puede ser directamente, en secreto, dándolo a una persona que se encuentra necesitada, o hacerlo a través de la caja de los pobres que hay en la mezquita, y desde allí se distribuye entre los que lo necesitan, y que lo han solicitado.

La solidaridad en el Islam no solo se circunscribe a los musulmanes sino que se hace extensiva a toda la humanidad, independientemente del credo religioso de los beneficiarios. En la mayoría de las mezquitas directamente, o a través de asociaciones, se realiza una acción social de carácter asistencial y de atención a necesitados, y funciona una importante red social de acogida que facilita las primeras fases de inserción. Entre sus campos de intervención destacamos:

$1^{\circ}$ ) Informativa y de inserción para la población recién llegada. Consiste en informar y orientar sobre las gestiones administrativas que deben realizar cuando llegan a la sociedad de acogida. Además de proporcionar otras ayudas complementarias como cursos de alfabetización, aprendizaje de español y árabe -a fin de que los nacidos ya en la sociedad de acogida no olviden la lengua de sus progenitores-, asesoramiento jurídico, sanitario, etc. No obstante, la amplitud de las prestaciones que realiza cada comunidad depende del grado y tiempo de inserción en el territorio y de su nivel de relación con instituciones públicas y privadas, del número de miembros y de sus recursos económicos y personales disponibles.

$2^{\circ}$ ) Ayuda a la población en sus necesidades básicas. Desde las mequitas, y según sus posibilidades, se realizan programas y acciones de ayuda para cubrir las necesidades más inminentes de los miembros de la comunidad. En ciudades más grandes, en donde la comunidad islámica lleva asentada

40 La cuantía de la limosna representa una parte de la renta recibida, comprendida entre el $10 \%$ y el $40 \%$, y ha pasado a convertirse en muchos países musulmanes en un impuesto sobre la renta de las personas físicas. 
más tiempo y dispone de mayores recursos, se promueven actividades colectivas. Un ejemplo de ello, en la mezquita de Fuengirola (Málaga) se está realizando un Programa de Ayuda Social consistente en proporcionar a 400 familias residentes en la provincia de Málaga, comidas, ropas, materiales escolares y ayuda económica. En Ceuta, a través de la ONG, «Luna Blanca», creada en 2003, se atiende menores no acompañados que se encuentran viviendo en la ciudad, se dispone de un comedor social, se reparten alimentos durante el mes del Ramadán, se asiste a familias desfavorecidas, se presta asistencia jurídica y social a inmigrantes, etc.

Existen asociaciones en las principales ciudades españolas que realizan funciones parecidas, y que depende de FEERI (Federación Española de Entidades Religiosas Islámicas) y UCIDE (Unión de Comunidades Islámicas de España). En estas asociaciones, los miembros más asentados en el barrio o ciudad, ejercen una función de mediación entre los recién llegados y las administraciones locales, y les ayudan en la solución de sus problemas y para la obtención de los correspondientes permisos, empadronamiento, tarjeta sanitaria, escolarización, acompañamiento a centros sanitarios, entre otros apoyos. Se trata de una auténtica red de solidaridad y ayuda en las primeras necesidades del inmigrante: información, recursos materiales, apoyo administrativo, laboral, etc.

A partir de los años noventa, UCIDE desarrolla una importante acción social a través del programa Muhayir (el inmigrante), y recibe algunas subvenciones públicas para el desarrollo de esta función. Realiza también otras actividades para favorecer la inserción de los inmigrantes como la alfabetización, especialmente de las mujeres, la bolsa de trabajo, el banco de alimentos, la asesoría jurídica, etc. La mayor parte de las tareas las hacen voluntarios, y se favorece la implicación de mujeres en la gestión de estas actividades, principalmente las que tienen un nivel formativo superior.

\section{Comunidad Judia}

El origen de la Comunidad Judía en la Península Ibérica son las comunidades sefaradíes, expulsadas a finales del siglo $\mathrm{XV}$, y que se diseminaron principalmente por la cuenca del Mediterráneo. Los judíos españoles expulsados siguieron desarrollando sus particularidades cultuales y culturales. Una pequeña minoría de ellos todavía mantienen como lengua familiar el ladino o sefardí, una variante de castellano que incluye numerosas palabras hebreas. Muchos de ellos portan apellidos españoles. Son minoritarios en el judaísmo actual y representan un sexto del judaísmo mundial, y se localizan principalmente en el Estado de Israel. En España son una minoría que no debe superar los 40.000 miembros, entre los que hay un buen número de no religiosos. Su actividad religiosa se desarrolla en la sinagoga y en grupos reducidos, que constituyeron la Federación de Comunidades Judías de España (FCJE).

En el judaísmo existe la obligación moral de asistir a las personas necesitadas. A esta obligación se la denomina tsedaká, y se basa en el principio de que los que tienen más recursos deben ayudar y ser solidarios con los necesitados, entendiéndose más que como caridad como justicia, y ser una forma de redistribución de bienes entre los miembros de la comunidad. Para ello existe una organización de acción social, denominada Ezrá, que se encarga de buscar recursos económicos y de repartirlos entre los necesitados, que casi siempre son de la propia comunidad, y 
que normalmente son personas mayores y ancianos y población procedente de otros países, especialmente de Sudamérica. Su acción social se dirige hacia los grupos más vulnerables intracomunitarios, centrándose principalmente en las personas de mayor edad. El colectivo de ancianos tiene una especial relevancia entre los judíos al ser considerados como transmisores de las costumbres y tradiciones, y se les protege y ayuda en sus necesidades, aunque suele hacerse de forma personal y privada.

Por miedo al antisemitismo y por razones de seguridad, las comunidades judías tienen una escasa proyección exterior. No obstante, en las sinagogas realizan campañas de recogida de donativos para ayudar a los afectados en catástrofes, guerras, etc.

\section{Testigos Cristianos de Jehová}

Movimiento cristiano bíblico surgido en Estados Unidos a comienzos del siglo XX. Desarrollan una visible labor de proselitismo. En España es uno de los grupos religiosos con mayor presencia, superan los 110.000 fieles, y tienen un gran número de centros de culto, principalmente en Barcelona, Madrid, Valencia, Alicante, Sevilla y Vizcaya, a pesar de sus escasos recursos económicos disponibles, los cuales se destinan principalmente a la evangelización, socorrer a las víctimas de desastres naturales, apoyar a los misioneros y ministros viajantes, construir lugares de reunión en países en vías de desarrollo e imprimir y enviar biblias y publicaciones cristianas. No tienen obras sociales propiamente dichas pero ayudan puntualmente a las personas necesitadas de la comunidad, asesorando y orientando a inmigrantes, visitando a presos, etc. Además sus recursos económicos suelen ser muy escasos ya que los Salones del Reino se mantienen con las aportaciones directas de sus fieles.

\section{Iglesia de Jesucristo de los Santos de los últimos Días}

En la actualidad tienen en torno a 55.000 seguidores y algo más de un centenar de lugares de culto. Tiene una organización centralizada y sus recursos provienen de sus propios miembros, que tiene la obligación de pagar el diezmo a la Iglesia, que lo dedica a la construcción de nuevos templos y a financiar proyectos humanitarios en el Tercer mundo.

$\mathrm{Su}$ acción social se concreta generalmente en diferentes campos: $1^{\circ}$ ) Educativo, a través de actividades lúdicas y recreativas con jóvenes y niños, principalmente durante los fines de semana; $2^{\circ}$ ) Mujeres, mediante reuniones informativas para buscar solución a sus problemas personales y familiares, y la realización de actividades de ayudas humanitarias. La Sociedad de Socorro es una organización existente en las Iglesias dedicada a ayudar a las mujeres en todas sus necesidades; $3^{\circ}$ ) Jóvenes mediante reuniones por grupo de edad, y realización de actividades lúdicas y creativas, así como otras solidarias en beneficio de la comunidad, barrio, etc.

A nivel internacional, algunas Iglesias colaboran en proyectos de cooperación con países de tercer mundo, a través de Cruz Roja o Cáritas.

\section{Budismo}

El Budismo no es una religión propiamente dicha desde la perspectiva occidental ya que carece de una doctrina basada en creencias inmutables, ni textos sagrados, ni practicas rituales, ni preceptos que cumplir. Es una filosofía y una opción universal 
que supone un estilo y forma de vida determinada. Tiene un carácter universalista, con una gran capacidad de adaptación a lugares, contextos e incluso opciones personales. Los budistas rondan los 400 millones en la actualidad, de los cuales hay en América unos cuatro millones y en Europa en torno a un millón. En España, el primer grupo budista se constituye en Ibiza y enseguida comienza a extenderse por otras ciudades y provincias. En la actualidad cuenta con varios monasterios y múltiples centros de meditación. Hay una gran diversidad de grupos y maestros, y las escuelas más extendidas son las tibetanas y la escuela zen, además de agrupaciones de origen japonés como Soka Gakkai. El número de budistas y simpatizantes en España supera las 40.000 personas, pero si se computa también a quienes siguen las formas del nuevo budismo o que habitualmente asisten a retiros, conferencias y acontecimientos, su número podría incrementarse significativamente. El mayor número de centros se encuentran en Barcelona, Madrid, Valencia, Islas Baleares y Alicante.

La acción social de los grupos budistas se centra en el mantenimiento de locales para el retiro y la reflexión, y en la formación personal para asumir este estilo y forma de vida. Por tanto, las publicaciones ocupan un papel importante.

\section{La acción social en las confesiones minoritarias desde la perspectiva de sus actores. El caso de Aragón}

La solidaridad confesional se basa en la idea de fraternidad universal entre los creyentes, que incluye comunidad de bienes, atención a los necesitados, etc. Y para llevar a término esta fraternidad, dada la complejidad de la sociedad contemporánea, las diferentes comunidades han tenido que institucionalizar su acción social en función del contexto sociológico. En primer lugar, promoviendo un mundo diferente, sin desigualdades ni discriminaciones por razón de raza, credo, ideología, y para ello, se han convertido en promotores de los derechos humanos y de las naciones, de la igualdad social y redistribución personal y territorial de la riqueza, de unas relaciones internacionales más justas y solidarias, etc.

Y además, en el ámbito local, promueven y desarrollan una importante acción social con las personas más débiles y necesitadas. La solidaridad se basa en la hermandad existente entre todos los hombres, por su condición de hijos de Dios, y se materializa a través de la organización social y política de la comunidad en beneficio de todos. La solidaridad es una forma de estar en el mundo, con el compromiso de mejorarlo, a través de comportamientos solidarios especialmente con los colectivos excluidos, marginados o con problemas de integración e inserción social ${ }^{41}$. Con ello, las organizaciones confesionales contribuyen, o incluso facilitan la integración e inserción social de los creyentes y simpatizantes con dificultades y desempeñan un papel importante como red de autoayuda y apoyo en la acogida a las personas que vienen desplazadas, y facilitan su inclusión en la sociedad de acogida ${ }^{42}$.

Las comunidades de creyentes crean espacios solidarios de encuentro para los que viven en una situación de inestabilidad personal, precariedad económica e indefensión social. Al tratarse de grupos no numerosos la ayuda y apoyo se realiza de

López et alter, 2007: 147.

42 Del Olmo, 2009: 33-69. 
una manera más directa. Destacar, por ejemplo, el papel que está teniendo la Iglesia Pentecostal de Filadelfia en la inserción e inclusión social de la población gitana española y rumana.

En España, las confesiones minoritarias hasta la consolidación de la transición democrática tuvieron que desarrollar su acción solidaria de una manera clandestina, y durante los últimos años del franquismo, tras la relativa apertura confesional que se produjo, de una manera discreta exclusivamente con sus creyentes. Con la Constitución de 1978, y la aprobación de la libertad de culto, sus intervenciones adquieren una dimensión universal y su atención social se dirige, en la mayoría de las ocasiones, a cualquier persona necesitada.

La religión es presentada también en la experiencia de los inmigrantes como un fenómeno que suscita hospitalidad, fraternidad y solidaridad y las comunidades de creyentes son valoradas como lugares de referencia, fuentes desde las que reconstruir la propia vida en el extranjero y organizaciones donde gestionar oportunidades de empoderamiento y movilidad social ${ }^{43}$.

El inmigrante,

Concibe a las instituciones religiosas como un lugar no sujeto a intereses y donde, en principio, no se pide nada a cambio. Esto hace que estas instituciones sean contempladas como lugar fiable ${ }^{44}$. La religión, en contextos migratorios, tiene capacidad para producir seres humanos que detestan las condiciones de vida impuestas por el destino ${ }^{45}$.

El importante papel que tienen las confesiones minoritarias en el proceso de integración e inclusión de la población inmigrante, al igual que sucede con la Iglesia Católica, aparece en la voz de los propios protagonistas, especialmente en cuestiones relacionadas con:

$\left.1^{\circ}\right)$ Ayuda administrativa. La principal preocupación de los inmigrantes cuando acceden a España es administrativa, es decir, regularizar su situación jurídica, conseguir permiso de trabajo y/o residencia, disponer de una vivienda, encontrar y mantener el empleo, tener tarjeta sanitaria, escolarizar a los hijos, etc. Y para ello acuden a la red familiar, amigos y compatriotas o directamente a las organizaciones no gubernamentales, asociaciones de inmigrantes y comunidades confesionales o Iglesias, en donde entran en contacto con otros que han pasado por una situación similar, y desde allí se les ayuda en sus necesidades básicas, como se refleja en las palabras de este dirigente de la comunidad islámica:

Desde la mezquita se ayuda a los recién llegados y se les acompaña al ayuntamiento para empadronarse, a sanidad para conseguir la tarjeta sanitaria, al colegio para escolarizar a los hijos menores, a las oficinas de empleo, etc. y que dispongan de los papeles necesarios para regularizar su situación cuanto antes ${ }^{46}$.

\footnotetext{
Buades y Vidal, 2007: 33.

Aparicio et alter, 1999:168.

Vidal y Martínez, 2006:17.

Informante 1.
} 
En casi todas las confesiones minoritarias, es el mismo pastor, sacerdote ortodoxo o responsable de la comunidad, o simplemente algún miembro de ella, quien frecuentemente acompaña a los recién llegados a regular su situación administrativa, sanitaria, laboral, educativa, etc. La vivencia de la fe lleva al creyente a desarrollar acciones solidarias de amplio espectro en beneficio de los miembros de la comunidad.

Primeros años iba más a la mezquita. Ellos me ayudaron a conseguir papeles y tarjeta de médicos... Luego cuando vino mi mujer e hija me ayudaron a ponerla en tarjeta, y a meterla en la escuela ${ }^{47}$.

$\left.2^{\circ}\right)$ Inserción Social. Las confesiones minoritarias crean redes sociales de ayuda y se convierten en espacios de encuentro y relación, donde se comparten intereses y se busca, junto con los demás, solución a los problemas y necesidades, consiguiendo con ello evitar o paliar situaciones de desarraigo, comunes a muchos de los que vienen, teniendo que dejar atrás su familia, amigos, costumbres, formas de vida para asumir otras nuevas, que a veces resultan muy distintas.

Reunirse y sentirse perteneciente a un grupo o una comunidad es una de las necesidades básicas de todo ser humano y no pocos la satisfacen por medio de grupos o comunidades religiosas ${ }^{48}$.

Los problemas de soledad, acompañados del desconcierto y temor que supone la adaptación a la realidad de la sociedad de acogida de las ilusiones y proyectos pensados en su país de origen, genera en muchos casos desesperación y frustración. Las comunidades de creyentes comparten los problemas del día a día, y sus miembros tienen la oportunidad de sentir el apoyo de sus amigos y compatriotas, y recibir muestras de cariño por parte de ellos.

Desde la iglesia se realiza un servicio de ayuda a los más necesitados, no sólo en necesidades básicas sino también se les ayuda en los trámites legales, y en ella también hacen amistades, dado que al principio se encuentran muy solos y... lo pasan mal. Cuando asisten a actos religiosos o participan en reuniones conocen a otras personas, y se establecen nuevas relaciones. Aquí saben que siempre tienen un lugar para estar con otros ${ }^{49}$.

Compartir no solo el rato de la lectura de la palabra, de la oración comunitaria, de los rezos diarios, sino también fines de semana, excursiones, paseos, etc. contribuye sin duda a minorar la soledad que produce el estar en un país muy diferente al suyo, y de alguna manera extraño, con costumbres y estilos de vida que en principio chocan o son muy diferentes a lo que hasta el momento han vivido.

Sí, cuando vine a España sólo conocía a una amiga, que me llevó a la iglesia (evangélica), y allí conocí mucha gente, muchos amigos y amigas... Allí voy cuando no

\footnotetext{
47 Informante 2.

48 Aparicio et alter, 1999:173.

49 Informante 3.
} 
tengo que cuidar al señor, otras veces con mis amigas de la iglesia vamos al cine, a pasear, a tomar algo al bar...Hay otra que también cuida a señora mayor, y vive cerca... y muchas tardes quedamos y damos un paseo, vamos de compras... ${ }^{50}$.

La iglesia se convierte en un espacio de encuentro en el que se pueden llegar a establecer relaciones personales y grupales, facilitando con ello los procesos de socialización y proporcionando un lugar para compartir los momentos de tiempo libre y conocer personas, y sentir el apoyo y la comprensión de la comunidad de creyentes, especialmente en los momentos de dificultades.

En la iglesia (adventista) me ayudaron mucho. He encontrado nuevos amigos, y me han apoyado en momentos de dificultades, como la enfermedad de mi hijo. Siempre nos hemos sentido acompañados ${ }^{51}$.

$3^{\circ}$ ) Inserción laboral. Muchas de estas organizaciones confesionales ayudan a la inserción laboral y social de los que acuden a ellas a través del asesoramiento laboral y ayuda en los trámites administrativos. En ocasiones, se aprovechan las instalaciones de la iglesia o lugar de oración para impartir cursos de español para extranjeros y otra formación dirigida a facilitar la inserción laboral.

La ayuda no se limita a proporcionar ropa, alimentos, sino que se intenta entre todos los miembros de la comunidad solucionar los problemas de las familias, y el principal de ellos es el trabajo. De manera que los que trabajamos estamos atentos, y cuando hay un puesto libre en nuestro taller, comercio, fábrica, oficina, etc., avisamos a los que están buscando trabajo. Esta es la principal ayuda que podemos dar ${ }^{52}$.

En otras ocasiones, es la propia comunidad de creyentes la que ayuda a buscar empleo a quien no lo tiene a través de sus propias redes, y acuden al parado cuando alguien necesita algún oficio para su casa (pintor, carpintero, albañil, fontanero, etc.), y de esta manera se les proporcionan unos ingresos. Existe una gran sensibilidad en este aspecto en casi todas las confesiones, como lo señalan estos informantes:

La Parroquia (ortodoxa) me ayuda a buscar trabajo, y los rumanos me llaman cuando tienen que hacer obra en su cocina, baños... además también puedo pintar. El sacerdote hace que la gente me ayude y me dé algo de trabajo... No quiero volver a Rumanía, allí es peor ${ }^{53}$.

Este es un claro ejemplo de la vinculación existente entre la institución eclesial, a través de la figura del sacerdote, pastor o responsable con los feligreses, y un ejemplo de la acción social que se desarrolla, y que resulta crucial para facilitar los procesos de integración en la sociedad de acogida.

\footnotetext{
Informante 4.

Informante 5.

Informante 1.

Informante 6.
} 
Mi Iglesia (Evangélica) me buscó trabajo cuando cerró la tienda. Me buscaron para cuidar un señor mayor enfermo. Mejor, ya que no pago casa ni comida, y lo que gano puedo mandarlo a casa, y ellos están más contentos... Este es mejor trabajo. Tengo que estar muchas horas, pero me quiere mucho y también sus hijos ${ }^{54}$.

Por eso, los locales de culto y de oración se convierten en lugares de referencia para todos aquellos que tienen dificultades de inserción personal, social, laboral y residencial. Se trata generalmente de pequeñas comunidades o grupos con un reducido número de miembros por lo que casi todos se conocen y mantienen unas relaciones de amistad.

La acción social que realizan las confesiones religiosas se considera natural entre los creyentes. Para realizar estas funciones de carácter solidario, suelen constituir, en muchas ocasiones, asociaciones de carácter social o cultural, y de esta manera tener personalidad jurídica para establecer acuerdos con las administraciones públicas e instituciones privadas y poder participar en las convocatorias de ayudas y subvenciones que éstas convocan para fines de carácter social, ya que como tales confesiones no pueden participar, dado que España es un estado aconfesional, y como tal, no se puede subvencionar directamente actividades de carácter exclusivamente religioso. Este es el caso, por ejemplo, de la Iglesia Evangélica, que dispone de una organización no gubernamental, de ámbito nacional, como Diaconía, desde la que se coordina la intervención social, a través de sedes en las comunidades locales.

A fin de conseguir recursos, dado que disponemos de muy pocos, y los ingresos obtenidos de los creyentes se destinan mayoritariamente para atender gastos ordinarios de mantenimiento del local, las Federaciones disponen de Organizaciones no gubernamentales, asociaciones culturales, que participan en convocatorias públicas para obtener ayudas para actividades de inserción social, culturales, educativas, etc. ${ }^{55}$.

En el caso de las comunidades islámicas la ayuda y atención a las necesidades de sus miembros se hace de una manera directa por parte de los creyentes. Se dispone de escasos recursos que se obtienen de aportaciones voluntarias y de las colectas especiales que se recogen en días señalados, como final del Ramadán, en donde el creyente aporta en función de sus ingresos- El musulmán debe cumplir con el mandato de Al·lâh, de repartir su suerte con otros hermanos necesitados, que tienen dificultades para cubrir sus necesidades básicas al haber tenido menores oportunidades, tal y como se recoge en el Corán. Para la realización de actividades sociales, culturales y formativas se crean asociaciones a través de las cuales participan en las convocatorias de ayudas públicas.

Las ayudas públicas son muy reducidas, y son para acciones muy específicas como un curso, una actividad cultural, un taller... y para poder acudir a ellas tenemos que hacerlo a través de asociaciones dado que como mezquita no se puede, por

\footnotetext{
Informante 4. Informante 7 .
} 
su carácter religioso. Pero no hay ningún tipo de subvención para contribuir a sufragar el coste de locales (alquiler, luz, mantenimiento, etc.) que tiene que ser asumido por todos los hermanos en función de sus recursos, los cuales casi siempre son muy reducidos, especialmente en estos últimos años ${ }^{56}$.

La inmigración constituye una de las áreas prioritarias de intervención social de las confesiones minoritarias en España, especialmente en estos momentos de crisis, dado que está siendo uno de los colectivos más afectados por la globalización económica y las guerras.

Los grupos y comunidades religiosas siguen cumpliendo con su función de favorecer sentimientos de pertenencia y de interdependencia grupal; sólo que, ante una población desarraigada y excluida o en claro peligro de exclusión, esa función se convierte en la más destacada por los propios inmigrantes ${ }^{57}$.

Las ayudas materiales se realizan de manera informal, en las propias iglesias, comunidades y mezquitas, y más formalmente a través de asociaciones y organizaciones constituidas con la finalidad de realizar una acción social. El primer contacto que, en muchas ocasiones, tiene el inmigrante con las instituciones religiosas ubicadas en España

Es en demanda de ayudas materiales: albergue, comida, trabajo, dinero... Los espacios religiosos son una más de las muchas puertas a las que llaman y no pocas parroquias, mezquitas o cualquier otro tipo de iglesia dan algún tipo de cobertura a estas demandas (...) Y cuando se trata de confesiones minoritarias, este acercamiento en busca de orientación y ayuda práctica adquiere un carácter especial. Aquí no es una puerta más, sino la puerta que proporciona una ubicación social y una pertenencia a un grupo muy concreto donde conseguir contactos muy valiosos $^{58}$.

\section{Conclusión}

Las grandes religiones han contribuido, sin duda, al desarrollo y puesta en práctica de los derechos humanos y a la configuración de una ética universal, al apostar por la paz, la no violencia y el respeto a la vida y a la naturaleza, la tolerancia, la solidaridad y un orden económico justo, la igualdad de derechos y por la hermandad entre todos los seres humanos sin distinción de razas, credos, ideologías, etc. En la actualidad, la mayor parte de ellas asumen y hacen suyos muchos de los planteamientos solidarios de los movimientos sociales que surgen y se desarrollan en la sociedad civil. Se cumple la función que Weber ${ }^{59}$ señalaba a la religión, a la que consideraba capaz de promover un espíritu de fraternidad universal a través de valores de solidaridad, justicia social, etc.

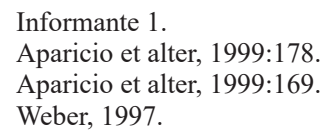


La solidaridad forma parte de la creencia, y el compromiso con los que sufren y están necesitados, principalmente con los más próximos, constituye una actitud que rige el comportamiento de muchos creyentes de estos grupos minoritarios.

La existencia de redes asistenciales y de apoyo en la mayoría de las confesiones minoritarias es una de las razones por las que estas comunidades están experimentado un progresivo crecimiento durante estas últimas décadas en España, debido principalmente a la vinculación existente entre ellas y la atención a las personas necesitadas autóctonas e inmigrantes. Ante la complejidad de la vida moderna, hay personas que buscan apoyo y compañía en la religión, especialmente cuando acceden a una sociedad que no es la suya y en la que, al menos al principio, se encuentran extraños.

La red social de las iglesias, mezquitas y comunidades ayuda a que los procesos de socialización e integración en la sociedad de acogida se desarrollen de forma más fácil y satisfactoria, cumpliendo con ello la función de compensación y de integración y cohesión social que Parsons ${ }^{60}$ otorgaba a la religión.

\section{Bibliografía}

A. Alaminos Chica, C. Penalva Verdú, e Y. Domenech López, «Reacciones comunitarias a la crisis económica y social en España», Azarbe, 3, 2014, 47-53.

R. Aparicio, A. Tornos, y J. Labrador, Inmigrantes, integración, religiones, Universidad Pontificia de Comillas-ICAI-ICADE, Madrid, 1999.

P.L. Berger, Para una teoría sociológica de la religión, Kairós, Barcelona, 1981.

P.L. Berger, El dosel sagrado: para una teoría sociológica de la religión, Editorial Kairós, Barcelona, 2006.

J. Buades Fuster, J. y F. Vidal Fernández, Minorías de lo mayor. Minorías religiosas en la Comunidad de Valencia, Icaria Editorial, Barcelona, 2007.

J. Buades, Amic(s) e amat(s). Minorías religiosas en las Illes Balears, Icaria Editorial, Barcelona, 2016.

R, Briones, S. Tarres y O. Salguero, Encuentros. Diversidad religiosa en Ceuta y en Melilla, Icaria Editorial, Barcelona, 2013.

R. Briones (dir.), ¿Y tú (de) quién eres? Minorías religiosas en Andalucía, Icaria Editorial, Barcelona, 2010.

C. Campo Sánchez, «Metodología y voluntariado», Documentación Social, 104 (1996), 149165.

W. Carrero-Albornoz, «La educación en valores como fortalecimiento de la democracia», Revista de Ciencias Sociales, Universidad del Zulia (Venezuela), vol. XIX, 3, 2013, 577587.

F. Díez de Velasco (ed.), Religiones entre continentes. Minorías religiosas en Canarias, Icaria Editorial, Barcelona, 2008.

J. Estruch, J, Gómez i Segalà, M. de M. Griera y A. Iglesias, Las otras religiones: Minorías religiosas en Cataluña, Icaria Editorial, Barcelona, 2007.

C. Gómez Bahillo (coord.), Construyendo redes. Minorías religiosas en Aragón, Icaria Editorial, Barcelona, 2009. 
B. López García, Á. Ramírez Fernández, E. Herrero Galiano, S. Kirhlani y M. Tello Weiss, Arraigados: Minorías religiosas en la Comunidad de Madrid, Icaria Editorial, Barcelona, 2007.

J. De Lucas, El concepto de solidaridad, Fontamara, México, 1993.

J. De Lucas, «Multiculturalismo y derechos», en J.A. López García y J.A. Del Real, Los derechos entre la ética, el poder y el derecho, Dykinson-Universidad de Jaén, Madrid, 2000a.

J. De Lucas, «Inmigración, ciudadanía, derechos: el paradigma de la exclusión», en M.E. Rodríguez Palop y A. Tornos (eds.), Derechos culturales y derechos humanos de los inmigrantes, Universidad Pontificia de Comillas, Madrid, $2000 \mathrm{~b}$.

N. Del Olmo Vicén, «Inmigración y religión» en C.Gómez Bahillo, A. Sanz Hernández, N. del Olmo Vicén y C. Franco de Espés Mantecón, Construyendo redes. Minorías religiosas en Aragón. Icaria Editorial, Barcelona, 2009, 33-69.

Diaconía, Red de Acción Social, Acción Social 2013. Iglesias y ONGs protestantes en España. FEREDE, Madrid, 2014.

E. Durkheim, Las formas elementales de la vida religiosa, [1895], Alianza Editorial, Madrid, 2008.

E. Galeano, Las venas abiertas de América Latina, Siglo XXI, México, 1971.

J. García Roca, «Globalización económica y solidaridad humana», en J.F. Martín Seco, La globalización y sus excluidos, Editorial Verbo Divino, Estella (Navarra), 2002.

A.M. González, Sociedad civil y solidaridad, Ariel, Barcelona, 2002.

M. Hernando de Larramendi y P. García Ortiz (dirs.), religion.es. Minorías religiosas en Castilla-La Mancha, Icaria Editorial, Barcelona, 2009.

M. Horkheimer, La teoría crítica, Barral editores, Barcelona, 1973.

M. Horkheimer, Anhelo de justicia. Teoría crítica y religión. Trotta, Madrid, 2000.

A. Izquierdo Escribano (dir.), Mareas de pluralismo. Minorías religiosas en Galicia, Icaria Editorial, Barcelona, 2014.

E. Kant, Crítica de la razón práctica, [1788], Alianza Editorial, Madrid, 2000.

E. Kant, La metafísica de las costumbres, [1797], Editorial Tecnos, Madrid, 2008.

R. Lasheras Ruiz, Umbrales. Minorías religiosas en Navarra, Icaria Editorial, Barcelona, 2012.

Ministerio de Justicia, Real Decreto 593/2015, de 3 de julio, por el que se regula la declaración de notorio arraigo de las confesiones religiosas en España (Boletín Oficial del Estado de 1 de agosto).

Á. Montes del Castillo y $\mathrm{M}^{\mathrm{a}} \mathrm{J}$. Martínez Martínez, Diversidad cultural y religión. Minorías religiosas en la Región de Murcia, Icaria Editorial, Barcelona, 2011.

T. Parsons, «El papel desempeñado por las ideas en la acción social», en Ensayos de teoría sociológica, [1949], Paidós, Buenos Aires, 1967.

J.J. Rousseau, El Contrato Social, [1762], Espasa Libros, Madrid, 2000.

J.J. Rousseau, Discurso sobre el origen y los fundamentos de la desigualdad entre los hombres, [1754], Ediciones Folio, Barcelona, 2007.

E. J. Ruiz Vieytez (dir.), Pluralidades latentes. Minorías religiosas en el País Vasco, Icaria Editorial, Barcelona, 2010.

H. de Saint-Simón, Catecismo político de los industriales, [1824], Hyspamérica, Madrid, 1985.

H. de Saint-Simón Nuevo cristianismo, [1825], Biblos, Buenos Aires, 2002.

J. A. Valero Matas (dir.), y S. Miranda Castañeda (coord.), Hablando de lo religioso. Minorías religiosas en Castilla y León, Icaria Editorial, Barcelona, 2012. 
F. Vidal y J. L. Martínez, Religión e Integración social de los inmigrantes: La prueba del Ángel, Universidad Pontificia de Comillas, Madrid, 2006.

M. Weber, Economía y Sociedad, [1921-1922], Fondo de Cultura Económica, Madrid, 1993.

M. Weber, Sociología de la religión, Istmo, Madrid, [1921], 1997.

M. Weber, La ética protestante y el espíritu del capitalismo, [1905], Alianza Editorial, Madrid, 2001.

\section{Webgrafía}

Fundación Pluralismo y Convivencia. Observatorio del Pluralismo Religioso en España. http://www.observatorioreligion.es/ (última actualización 1-12-2016). (acceso 1-10- 2016). Fundación Pluralismo y Convivencia. Convocatorias y Acuerdos de Resolución http://www. pluralismoyconvivencia.es/ayudas/linea_1/index.html (acceso 1-12-2016).

Iglesias evangélicas

http://www.protestantedigital.com (acceso 12-5-2015).

http://accionsocialprotestante.org (acceso 12-5-2015).

http://www.remar.org/queesremar1.html (acceso 12-5-2015).

http://www.misionurbana.org/ (acceso 12-5-2015).

http://www.lupaprotestante.com/blog/se-constituye-la-federacion-de-las-misiones-evangelicas-urbanas-de-espana/ (acceso 12-5-2015).

Iglesias biblicas

Iglesia de Jesucristo de los Santos de los Últimos Días (Mormones).

www.lds.org (acceso 12-6-2015).

Iglesia adventista del Séptimo Día

http://adventista.es/ (acceso 12-6-2015).

http://www.adra-es.org (acceso 12-6-2015).

Comunidades islámicas

http://ucide.org/ (acceso 12-8-2015).

http://feeri.es/ (acceso 12-9-2015).

INE. Cifras de Población a 1 de enero 2016. Datos provisionales

http://www.ine.es/prensa/np980.pdf (acceso 12-9-2015).

Instituto Aragonés de Estadística. Población y Hogares 2016.

http://www.aragon.es/estaticos/GobiernoAragon/Organismos/InstitutoAragonesEstadistica/

Documentos/docs/Areas/DatosBasic/2017/02_Poblacion_Hogares.pdf (acceso 12-122015).

\section{Análisis cualitativo}

Para la selección de informantes se ha solicitado la colaboración de un representante de la Iglesia Evangélica Española por su larga trayectoria histórica y porque la mayor parte de sus creyentes son población autóctona con una larga trayectoria familiar vinculada al protestantismo, y de responsables o creyentes de las confesiones minoritarias que mayor volumen de inmigrantes tienen entre sus fieles. Por una parte, se ha recabado la opinión de personas que tienen un cierto nivel de responsabilidad dentro de la comunidad o iglesia. En segundo lugar, se ha seleccionado a miembros de la comunidad, de origen extranjero ya asentados en España, con el fin de recoger su opinión sobre la ayuda y apoyo recibido por parte de la confesión en su proceso de inserción social. 


\section{Informantes}

Informante 1. Marroquí, responsable comunidad islámica, 19 años en España.

Informante 2. Argelino, musulmán, 9 años de residencia en España.

Informante 3. Boliviana, representante de la Iglesia de Betel, 11 años en España.

Informante 4. Ecuatoriana, evangélica-Asamblea de Hermanos. 8 años residencia en España.

Informante 5. Española, adventista desde hace 4 años.

Informante 6. Rumano, ortodoxo, 10 años residencia en España.

Informante 7. Español, Iglesia Evangélica Española, representante de Diaconía.

\section{Guión de entrevista a los miembros y responsables de la comunidad de creyente}

1. Identificación.

2. Acción social que se desarrolla en la confesión a nivel institucional.

3. ¿Cuál es el apoyo solidario que desde vuestra confesión se da a las personas que acuden buscando ayuda? ¿En qué consiste? ¿Qué tipo de ayudas se proporciona? ¿Cómo se hace? ¿Qué redes sociales se crean?

4. ¿La iglesia, mezquita, lugar de oración... se ha convertido en una referencia de encuentro y de relación entre los que acuden a ella? ¿es un espacio de referencia solidaria? 